\title{
BMJ Open Quality Financial incentives linked to quality improvement projects in Swedish primary care: a model for improving quality of care
}

Rita Fernholm, ${ }^{\oplus 1,2}$ Eva Arvidsson, ${ }^{\oplus, 4}$ Björn Wettermark ${ }^{1,5}$

To cite: Fernholm R, Arvidsson E, Wettermark B. Financial incentives linked to quality improvement projects in Swedish primary care: a model for improving quality of care. BMJ Open Quality 2019;8:e000402. doi:10.1136/ bmjoq-2018-000402

Received 7 April 2018 Revised 18 April 2019 Accepted 22 April 2019

\section{Check for updates}

(c) Author(s) (or their employer(s)) 2019. Re-use permitted under CC BY-NC. No commercial re-use. See rights and permissions. Published by BMJ.

${ }^{1}$ Stockholm Region, Public Healthcare Services Committee, Stockholm, Sweden

${ }^{2}$ Division of Family Medicine and Primary Care, Department of

Neurobiology, Care Sciences and Society, Karolinska Institutet, Huddinge, Sweden

${ }^{3}$ Research and Development unit for Primary Care, Futurum, Jönköping, Sweden

${ }^{4}$ Jönköping Academy for Improvements of Health and Welfare, School of Health and Welfare, Jönköping University, Jönköping, Sweden

${ }^{5}$ Centre for

Pharmacoepidemiology, Department of Medicine, Karolinska Institute, Stockholm, Sweden

Correspondence to Dr Rita Fernholm; rita.fernholm@gmail.com

\section{ABSTRACT}

Background Quality improvement (QI) is necessary in all healthcare, but quality of healthcare is hard to measure. To use financial incentives to improve care is difficult and may even be harmful. However, conducting QI projects is a well-established way to increase quality in healthcare.

Problem In 2015, there were few QI projects conducted in primary care in the Stockholm Region, Sweden. There was no structured support or way to share the QI projects with other general practitioner (GP) practices. To use financial incentives could increase the number of projects performed and could possibly improve the quality of care. The aim was to increase the number of GP practices performing QI projects in the Stockholm Region through financial incentives.

Method To study QI projects performed during 2016 and 2017 in the Region Stockholm. This was compared with 2015 in Stockholm and with the Region Jönköping in Sweden during 2016 and 2017.

Interventions First, the healthcare administration started to reimburse GP practices for conducting and reporting Ql projects in 2016. Second, a 4-hour course in QI was offered. Third, feedback on plans for QI projects was given. The year after the projects were prerformed, they were published online to stimulate sharing and inspiration between the GP practices.

Results For 2016, there were $166(80 \%)$ of the GP practices that presented a QI project and in 2017, 164 $(79 \%)$ did so. The number of projects in Stockholm increased almost by 100 per years compared with 2015 . Conclusion QI work has increased in Stockholm since 2016, probably because of the financial incentives from the Stockholm Region.

\section{INTRODUCTION \\ Problem}

Quality of healthcare is hard to measure. There are many factors to take into consideration besides traditional measures, such as knowledge, clinical skills and person-centred care. ${ }^{1}$ However, despite the measuring problems, it is clear that quality improvement (QI) is necessary in all healthcare, including primary care/family medicine. Systematic approaches to perform QI projects has shown to have an effect. ${ }^{2}$ However, in many general practitioner (GP) practices, the knowledge about methods for QI is low. Additionally, the working environment is stressful that limits the time for QI work. Another obstacle has been difficulties to obtain data for measurements. With electronic patient records (EPR) in all primary care in Sweden, this problem is partly solved. In 2015, there were few QI projects conducted in the Stockholm Region, less than 75 projects in an area of 207 GP practices. There was no structure to share the QI projects with other GP practices.

\section{Available knowledge}

Audit and feedback (A\&F), that is, collecting data on clinical performance and report back with the purpose to stimulate QI, can be effective for improving quality in healthcare. ${ }^{34}$ However, A\&F together with financial incentives in different pay-for-performance schemes (P4P) is highly debated. Questions about if P4P has any positive effects at all, as well as about possible negative effects, are raised ${ }^{5-7}$ Studies suggest that positive results are mainly achieved by better documentation of the performance parameters, not better outcomes for patients. ${ }^{89}$ A review article from 2017 concludes that the patient outcome of P4P are unclear. ${ }^{10}$ GPs throughout Europe oppose the use of quality indicators for P4P, and a recent position paper on this was endorsed by WONCA (World Organization of National Colleges, Academies and Academic Associations of General Practitioners/Family Physicians) Europe in 2018. ${ }^{11}$

Yet, P4P is used in many European countries, often in combination with other payment systems, such as capitation. Examples of countries using $\mathrm{P} 4 \mathrm{P}$ are Israel, Sweden, Croatia, the Czech Republic, Estonia, Hungary, Italy, Latvia, Lithuania, the Netherlands, Spain, Canada, Australia, New Zealand and the USA. ${ }^{12}$ Some European countries have extensive $\mathrm{P} 4 \mathrm{P}$ schemes, for example, Belgium, France and the UK. 
The measurements cover different aspects of quality in primary care, such as access, clinical performance, costs and equity. ${ }^{13}$

In the UK, a P4P scheme, the Quality and Outcomes Framework (QOF), was introduced in 2004. ${ }^{14}$ QOF has been criticised for a number of reasons: displacement of non-rewarded goals, decreasing improvement when targets are reached and outcomes worse than before when goal-based remuneration is removed. Furthermore, replacement of the patient's own agenda with data gathering for the indicators, as well as reduced continuity after the QOF was introduced has been shown. ${ }^{15-18}$ The QOF is now abandoned in Scotland.

In France, a voluntary $\mathrm{P} 4 \mathrm{P}$ scheme for primary care physicians was introduced in 2009, the Contract for Improving Individual Practice. Only one-third of the GPs joined and the evaluations of the scheme raised questions about the ethical consequences. ${ }^{19} 20$

In the USA, data for the Healthcare Effectiveness Data and Information Set (HEDIS) has been collected since the beginning of the 1990s. The purpose was to find measures for comparison between healthcare systems, not measures for QI. However, the HEDIS is used for P4P. Criticism concerns data collection taking too much time, change of the focus for the consultation as in the $\mathrm{UK}^{21}$ and also that the measures do not necessarily reflect 'good care' but leads to the risk of overdiagnosis and overtreatment. $^{22}$

To use other payment systems, rather than $\mathrm{P} 4 \mathrm{P}$, to achieve high-quality primary care are suggested, ${ }^{23}$ as are mixed payment systems. ${ }^{12}$ The idea is to counterbalance some of the shortcomings of each payment method. Using financial incentives to improve care is difficult, ${ }^{24}$ but funding connected to the performance of more complex QI project has, to the best of our knowledge, not been studied before. Conducting QI projects is a well-established way to increase quality in healthcare. ${ }^{2}$ For A\&F, the base of P4P systems, the goal usually can be scribed as 'increasing desired behaviour' rather than 'finding new efficient ways to improve healthcare', which is the deeper goal of QI.

\section{Rational}

The GP practices in Stockholm have earlier adopted well to changing criteria for financial incentives. To conduct QI projects has not been a part of these incentives in Stockholm before 2016, but the model has been used in the Jönköping Region since 2010. In Jönköping, the GP practices have conducted and presented QI projects yearly, which has been a source of learning within the practices and between the different practices in the region.

\section{Specific aims}

To increase the number of GP practices performing QI projects in the Stockholm Region through financial incentives.

\section{METHODS}

\section{Context}

A GP practice in Sweden usually consists of GPs, nurses, assisting nurses, psychologists, physiotherapists and secretaries. The GP practices are the primary contact for most patients through phone, visit or the internet. All primary care is publicly financed through taxes, public as well as private GP practices. Sweden consists of 21 semi-autonomous regions, all having slightly different reimbursement systems for primary care. Usually, the financing is based mainly on capitation, but details can change from year to year. The capitation usually depends on age, burden of diseases and social economic status of the patients. A few percentages of the financing are usually based on quality measures, such as, for example, blood pressure levels, low antibiotic prescribing or accessibility. Stockholm region has been an exception and in 2015, only $40 \%$ was based capitation and $57 \%$ was based on the number of consultations/fee-for-service. An overview of primary care in western Europe is given by Gervas $e t a t^{25}$ and about the Swedish healthcare system by Anell et al. ${ }^{26}$

Stockholm region has 2.3 million inhabitants. Stockholm had 207 GP practices in 2016 and 208 GP practices in 2017, one-third of them public and two-thirds of them run by different private caregivers (all publicly financed). The size of the practices differs from caring for approximately 600 to 34000 inhabitants. Jönköping region is considerably smaller than Stockholm. Jönköping has 355000 inhabitants, 46 GP practices (30 public and 14 private, all publicly financed) with between 2000 and 15 000 inhabitants linked to each practice.

QI projects at GP practices are initiated for different reasons: from staff seeing a need to improve, staff feeling obliged to get the financing for a QI project and by residents as part of their specialist training.

\section{Interventions}

There were three interventions in Stockholm. First, the healthcare administration started to reimburse GP practices for conducting and reporting QI projects in 2016. Area of improvement was chosen by the practice, based on interest and need. The sum was $€ 0.5$ per inhabitant registered with the practice, paid to all practices that carried out a QI project, and also presented it in written form. Second, a 4-hour course in QI was offered in 2016 for participants in the local projects (30 practices attended). Third, feedback on plans for QI projects was given from the health administration to those who requested it (28 practices in 2016 and 150 practices in 2017). The year after the projects were performed, they were published online to stimulate sharing and inspiration between the GP practices.

As a comparison, in Jönköping, the healthcare administration has paid GP practices $€ 5$ per registered inhabitant for carrying out yearly QI projects since 2010. The requirements include a written plan for the QI project, defined measurements, and a poster and oral presentation of the results of the QI project at an annual regional 
conference. All GP practices are offered an external personal coach and the staff at the centres is offered a short course on QI methodology. The primary care unit for research and development in Region Jönköping also visits each GP practice annually with an A\&F report on their results with the purpose to promote and inspire QI work since 2006. The goal since the start has been that all GP practices should 'pass' and be fully paid for their QI projects, so the focus for the health administration is support and coaching. Usually, all but one or two GP practices achieve the requirements for funding.

All projects are documented by the local improvement teams using the A3 method ${ }^{27}$ and analysed by the healthcare administration to see if they fulfilled the requirements for payment. Many of the GP practices perform more than one QI project each per year and quite a few projects last over more than a year. However, every practice reports only one or two of their projects, that is, those connected to the reimbursement. Each resident in family medicine has to perform, or take active part in, a QI project and these are not part of the projects for the reimbursement.

In 2016, each GP practice had to report two projects, one connected to lifestyle interventions or other forms of preventive care, one of their own choice. In 2017, they only had to report one. For both years, the projects should include collaboration with at least one other actor (other healthcare unit, municipality or another healthcare actor).

\section{Study of the interventions}

Number of QI projects in Stockholm during 2016 and 2017 were assessed, as well as their content. This was compared with the number of QI projects during 2015 when there were no financial incentives for conducting QI.

In Jönköping, the number of reported projects were noted as well as their content. Residents projects are mandatory and outside of the study. The content of the projects partly depends on the requirements for the reimbursement.

\section{Measures and analysis}

Besides the number of QI projects, the content in the reports from the practices was evaluated. The area of the project was noted, and the quality of the project was measured.

In Stockholm, the projects were evaluated for quality using a scale of $1-5$, where evaluation 1 was used when there had been no intervention. That could, for example, be that the GP practices had made an inventory about how well they followed a guideline, or that they had interviewed some patients about the care given. Evaluation 2 was given when there had been an intervention but measures before or after were missing. Evaluation 3 was given when the project fulfilled basic criteria for an improvement project, that is, the presence of an intervention and measures before and after the intervention.
Evaluations 4 and 5 were used in projects with higher quality with an increasing level of collaborative work, person-centred care, results achieved and with a plan for further work. Evaluation 4 was used when one or two of these were included and 5 was used when three or four were included. The material from 2016 was compared with that from 2017. These 2 years were compared with 2015 with respect to the number of QI projects.

The systematic improvement projects in Jönköping were analysed in a 3-step scale. To receive full score, the projects had to include the following:

- In the second quarter each year: (i) Description of the improvement area and its relation to patients and their needs; (ii) Description of the overall goal and measurable subgoals, including a time for their fulfilments; (iii) Baseline measurements and (iv) Analysis of the current situation, ideas for improvement and prioritisation of ideas to be tested.

- In the fourth quarter each year: (i) Description of how the improvement work was carried out, including the collaboration with external actors and (ii) Results of measurements (changes in relation to baseline measurement and goals).

\section{Ethical considerations}

This study did not need approval by the Ethics Committee since it did not involve medical data or patient involvement. No medical charts were used and no contact with patients was made. The public was not involved. Data about the QI project are public and no individual practices can be identified in the study. An ethical aspect could be that hopefully some patients received better care thanks to the QI projects.

\section{RESULTS}

The 2016 was the first year that the Stockholm Region systematically organised, measured and evaluated the QI projects. In 2015, there were 75 projects that were known of. For 2016, there were 166 (80\%) of the 207 GP practices presented a QI project and in 2017, $164(79 \%)$ did so. The total number of QI projects in Stockholm increased almost by 100 per years compared with 2015 .

The subjects of the projects in Stockholm and Jönköping are displayed in table 1.

In Stockholm, two-thirds, 68\%, of the GP practices reported that they had improved their quality through their work (with EPR data to support their claims of improving chosen indicators).

There was no association between socioeconomic factors measured in CNI (Care Need Index,) of the area where the primary care GP practices was located and the quality of the projects.

One-fourth, 27\%, of the projects had elements of person-centred care but only one GP practice had a patient involved in the project planning group. Put simply, being person-centred is about focusing care on the needs of the person rather than the needs of the 
Table 1 Reported QI projects in Stockholm and Jönköping 2016

\begin{tabular}{|c|c|c|c|c|c|}
\hline \multicolumn{3}{|l|}{ Stockholm QI projects } & \multicolumn{3}{|l|}{ Jönköping QI projects } \\
\hline Subject & (n) 2016 & (n) 2017 & Subject & (n) 2016 & (n) 2017 \\
\hline Diabetes & 44 & 36 & Diabetes & 6 & 3 \\
\hline Chronic obstructive pulmonary disease & 14 & 52 & Chronic obstructive pulmonary disease & 6 & \\
\hline Congestive heart failure & 28 & 4 & Congestive heart failure & & 1 \\
\hline Prevention of stroke & 15 & 11 & Physical activity & 3 & 2 \\
\hline Accessibility to care & 3 & 5 & Diet/overweight & 5 & \\
\hline Patient safety issues & 14 & 0 & Alcohol & 1 & \\
\hline \multirow[t]{7}{*}{ Other } & 10 & 19 & Smoking & 1 & \\
\hline & & & Sick leaves/rehabilitation & 4 & 5 \\
\hline & & & Frequent visitors & 1 & 1 \\
\hline & & & Continuity & 1 & \\
\hline & & & Effective organisation & 4 & 5 \\
\hline & & & E-services & 4 & 1 \\
\hline & & & Accessibility to physiotherapists & 4 & 1 \\
\hline Total & 166 & 164 & Total & 89 & 45 \\
\hline
\end{tabular}

QI, quality improvement.

service. Examples from these projects were improved information material to patients, motivations interviewing technique and multidisciplinary support with education about the disease and what can be done for your own health. Furthermore, patients could borrow equipment to monitor blood pressure at home or they could choose to test their blood pressure in the waiting area accompanied by information about what to do with different kinds of results. There were also projects where patients could book an appointment directly to a psychologist instead of first having to see a GP for referral (in those practices, the

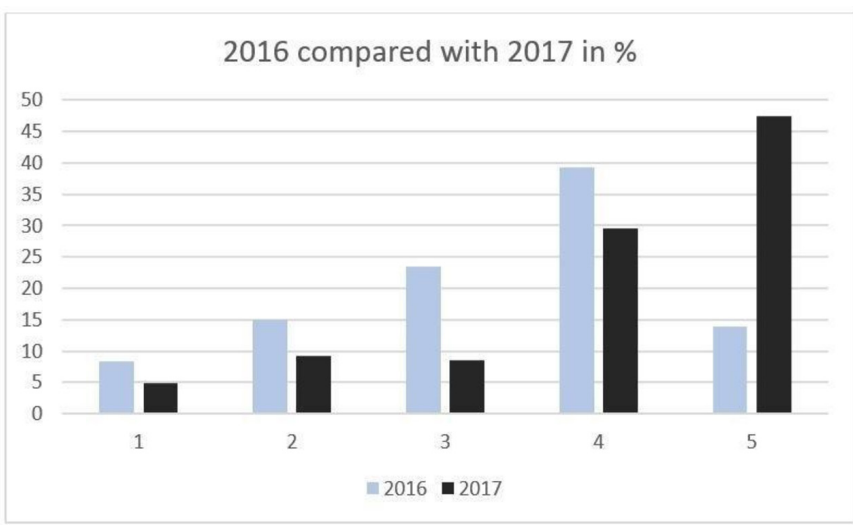

Figure 1 Quality of the QI work in 2016 and 2017 (Stockholm). QI, quality improvement.
GPs and the psychologists had close cooperation about the patients to see if they still should see a GP).

A collaborative approach had been used in $70 \%$ of the projects, that is, using more than one health profession in the QI work.

The projects were evaluated on a scale of 5 , see figure 1 , accordingly to the quality of their project with 5 representing the best. Details are described under measures and analysis. There was an evident increase in the quality of the works when comparing 2016 and 2017.

In Jönköping, one practice did not report any projects and one reported only one in 2016. In 2017, also, all but one reported projects. All reported project had full score.

A lot of the projects reflected the condition about preventive care. For example, the projects about the elderly, mental health and diabetes were about heather lifestyle for these patient groups. At least one-fourth of the projects also aimed to improve patients own control of their problems. Projects about organisation were, for example, planning for and with patients discharged from hospital using e-pads, increasing home visits, and continuity and cooperation with the municipality that organises home care for the elderly. Projects targeting a younger population was, for example, mental health and smoking cessation.

Over the years, there has been an increase in GP practices asking for help for extracting additional data (eg, 
to identify patient groups, individual patients and data for follow-up of results) from the EPR as part of their QI work.

\section{DISCUSSION}

\section{Summary}

With relatively low financial incentives (compared with Jönköping Region), it was possible to increase the number of QI projects in the Stockholm Region. During 2016, there were $80 \%$, and during 2017, there were $79 \%$ out of all GP practices to perform QI projects. That is, an increase of approximately $100 \mathrm{QI}$ projects/year compared with 2015. The quality of the projects increased from 2016 to 2017 following more support in the form of more feedback.

\section{Interpretation}

We found an evident increase in the number of QI projects in Stockholm after financial incentives were introduced. We also found an increase in quality in terms of following a structure for QI project in Stockholm. In Jönköping, the requirements for the projects has been harder each year, with no change in the funding, and yet almost all have passed every year. This indicates that GP practices perform QI projects of higher quality each year. Taylor et al. found in a systematic review that most QI included in the studies did not describe iterative cycles, small-scale change and/or iterative frequent measuring. ${ }^{28}$ In our study, these criteria were not included in the assessment, neither in Stockholm nor in Jönköping, so if they should be considered as 'real PDSA (Plan-Do-Study-Act) projects' is an open question.

The Jönköping model has also been running longer and includes higher funding per patient. Also, coaching and physical meetings where GP practices share ideas with each other, which both have an effect, ${ }^{29}{ }^{30}$ are parts of the concept. Hence, it is, therefore, difficult to compare the outcome between Stockholm and Jönköping.

In a systematic review from 2008, Schoen states that even if QI project may accelerate improvement, the effects on patient outcomes are modest. ${ }^{31}$ Likewise, the possible impact on patient outcome in our study is hard to measure. In Stockholm, some of the GP practices have reported improved quality measures. An example could be that more patients with diabetes get their yearly check-up or their eye exam. The effect of the project on the system is an increase in the interest about how to perform QI. There have been more GP practices that ask for education and support in their yearly QI project. The Stockholm Region has funded since 2016 and following these results the Region raised the funding to $€ 0.75$ per inhabitant for 2018 and 2019.

Also, in Jönköping, the effect on the health situation for the patients in the region, or any other outcome measures from the QI projects, has not been followed over the years. However, the GP practices own measurements show results of the QI projects, like in Stockholm.
Also, the requests for help with data reports to study baselines and follow-up measurements has increased over the years.

In the first years, focus on assessing the projects was on method and structure (eg, following the PDSA cycle, ${ }^{32}$ measurements, etc) rather than the actual effect of the projects. This affected the QI projects to focus on meeting the requirements for funding (structure and method) rather than results. Hence, evaluation of the projects has been redirected towards analysis, content and results. In 2016, the following criteria for reimbursement for the projects were added: 'The QI projects should be based on the needs of the patients and they should collaborate with at least one other actor (other healthcare unit, municipality or another healthcare actor)'. The years to follow will continue to be cycle in improving the models for stimulating QI work within primary healthcare.

\section{Strengths and limitations}

The major strength of the project was the large region where it was tested (2.3 million inhabitants in the Stockholm Region).

It was a limitation that we do not have a good follow-up of the actual effects of QI projects either in Stockholm or in Jönköping. The patients' groups targeted by each GP practices are small and the projects are short. We study the QI work and assume it has good effects if methods are used properly for patients who need it.

We also cannot be sure to what extent the funding had an effect since other factors, such as support, coaching and education, could also have an impact on the number and quality of the QI projects.

To what extent this approach is generalisable is hard to know. It depends on the context and system's financial reimbursement of primary care. Earlier studies have stressed the importance of evaluation of QI efforts over time and Walshe et al states that it is also known that the effectiveness of QI initiatives is, to a great extent, influenced by the organisational context. Characteristics, such as leadership, direction, organisational culture, training, resources and practical support, have been shown to be important factors. ${ }^{33}$ The balance between assessment (in relation to requirements for funding) and general support in an allowing atmosphere can be a delicate task. ${ }^{34}$ However, there could be a similar effect in other regions in Sweden or in other countries.

Another limitation in the study is that we have little knowledge of the QI projects in the Stockholm Region before 2016. They were not shared between the GP practices. There might be existing more than the 75 projects mentioned.

Patients were not involved in planning and performing the QI projects, except for one GP practice, but this is an area that needs to be more focus on. GP practices probably need support to facilitate patient involvement.

If the healthcare administration in Stockholm had requested a project plan from all GP practices in advance already in 2016, it might have enhanced the quality of 
the final projects since that would have allowed for additional support. In 2018 and 2019, it has been mandatory to send in a plan during the first part of the year, to allow for feedback.

\section{CONCLUSIONS}

QI work has increased in Stockholm since 2016, probably because of the financial incentives from the Stockholm Region. It seems sustainable since the Region have continued to reimburse and for 2018 and 2019, the amount was raised. In Jönköping, the QI has been part of the funding for the GP practices since 2010 and there are no plans of ending it. Spreading is probably possible, in Sweden and beyond. The next step in Stockholm is expanding the knowledge of systematic QI work. During 2019, a 5-day course over a period of 8 months is given to support QI work in the region.

Contributors RF researched the data for Stockholm and EA researched the data for Jönköping. RF and EA drafted the manuscript. All the authors contributed to the discussion, review and editing of the manuscript. RF and BW contributed to the study design.

Funding The study is funded by the Stockholm Region.

Competing interests None declared.

Patient consent for publication Not required.

Provenance and peer review Not commissioned; externally peer reviewed.

Open access This is an open access article distributed in accordance with the Creative Commons Attribution Non Commercial (CC BY-NC 4.0) license, which permits others to distribute, remix, adapt, build upon this work non-commercially, and license their derivative works on different terms, provided the original work is properly cited, appropriate credit is given, any changes made indicated, and the use is non-commercial. See: http://creativecommons.org/licenses/by-nc/4.0/.

\section{REFERENCES}

1. Holmboe ES, Lipner R, Greiner A. Assessing quality of care: knowledge matters. JAMA 2008;299:338-40.

2. Batalden PB, Davidoff $F$. What is "quality improvement" and how can it transform healthcare? Qual Saf Health Care 2007;16:2-3.

3. Brehaut JC, Colquhoun HL, Eva KW, et al. Practice feedback interventions: 15 suggestions for optimizing effectiveness. Ann Intern Med 2016;164:435-41.

4. Ivers N, Jamtvedt G, Flottorp S, et al. Audit and feedback: effects on professional practice and healthcare Outcomes. Cochrane Database Syst Rev 2012;6.

5. Hysong SJ, SoRelle R, Broussard Smitham K, et al. Reports of unintended consequences of financial incentives to improve management of hypertension. Plos One 2017;12:e0184856.

6. Ryan AM, Krinsky S, Kontopantelis E, et al. Long-term evidence for the effect of pay-for-performance in primary care on mortality in the UK: a population study. Lancet 2016;388:268-74.

7. Seddon J. Systems thinking in the public sector. Triarchy Press Limited, 2008.

8. Petersen LA, Woodard LD, Urech T, et al. Does pay-for-performance improve the quality of health care? Ann Intern Med 2006;145:265-72.
9. Rosenthal MB, Frank RG. What is the empirical basis for paying for quality in health care? Med Care Res Rev 2006;63:135-57.

10. Mandavia R, Mehta N, Schilder A, et al. Effectiveness of UK provider financial incentives on quality of care: a systematic review. $\mathrm{Br} J$ Gen Pract 2017;67:e800-15.

11. EQuiP. Measuring quality in health care-EQuiP position paper, 2010 , 2017.

12. OECD/EU. Health at a glance: Europe 2016 - state of health in the EU cycle. Paris: OECD Publishing, 2016.

13. Union E. A new drive for primary care in Europe: rethinking the assessment tools and methodologies. Report of the expert group on health systems performance assessment. S. O. T. E. G. O. H. S. P. A. European Commission. Luxembourg: Publications Office of the European Union, 2018.

14. Roland M, Guthrie B. Quality and outcomes framework: what have we learnt? BMJ 2016;354

15. Campbell SM, McDonald R, Lester $H$. The experience of pay for performance in English family practice: a qualitative study. Ann Fam Med 2008;6:228-34.

16. Campbell SM, Reeves D, Kontopantelis E, et al. Effects of pay for performance on the quality of primary care in England. $N$ Engl J Med 2009;361:368-78.

17. Chew-Graham CA, Hunter C, Langer S, et al. How QOF is shaping primary care review consultations: a longitudinal qualitative study. BMC Fam Pract 2013;14.

18. Maisey S, Steel N, Marsh R, et al. Effects of payment for performance in primary care: qualitative interview study. $J$ Health Serv Res Policy 2008;13:133-9.

19. Saint-Lary O, Boisnault $P$, Naiditch $M$, et al. Performance scores in general practice: a comparison between the clinical versus medication-based approach to identify target populations. PLoS One 2012;7:e35721.

20. Saint-Lary O, Plu I, Naiditch M. Ethical issues raised by the introduction of payment for performance in France. $J$ Med Ethics 2012;38:485-91.

21. Burns J. HEDIS is the hassle that became a habit. Manag Care 2017;26:16-19.

22. Saver BG, Martin SA, Adler RN, et al. Care that matters: quality measurement and health care. PLoS Med 2015;12:e1001902.

23. Forbes LJL, Marchand C, Doran T, et al. The role of the quality and outcomes framework in the care of long-term conditions: a systematic review. Br J Gen Pract 2017;67:e775-84.

24. Yuan B, He L, Meng Q, et al. Payment methods for outpatient care facilities. Cochrane Database Syst Rev 2017;3.

25. Gervas J, FERNA MP, Starfield BH. Primary care, financing and gatekeeping in Western Europe. Fam Pract 1994;11:307-17.

26. Anell A, Glenngard AH, Merkur S. Sweden health system review. Health Syst Transit 2012;14:1-159.

27. Jimmerson C, Weber D, Sobek DK. Reducing waste and errors: piloting lean principles at intermountain healthcare. Jt Comm J Qual Patient Saf 2005;31:249-57.

28. Taylor MJ, McNicholas C, Nicolay C, et al. Systematic review of the application of the plan-do-study-act method to improve quality in healthcare. BMJ Qual Saf 2014;23:290-8.

29. Wells S, Tamir O, Gray J, et al. Are quality improvement collaboratives effective? A systematic review. BMJ Qual Saf 2018;27:226-40.

30. Godfrey MM, Andersson-Gare B, Nelson EC, et al. Coaching interprofessional health care improvement teams: the coachee, the coach and the leader perspectives. J Nurs Manag 2014;22:452-64.

31. Schouten LMT, Hulscher MEJL, van Everdingen JJE, et al. Evidence for the impact of quality improvement Collaboratives: systematic review. BMJ 2008;336:1491-4.

32. Berwick DM. A primer on leading the improvement of systems. BMJ 1996;312:619-22.

33. Walshe K, Freeman T. Effectiveness of quality improvement: learning from evaluations. Qual Saf Health Care 2002;11:85-7.

34. Korlén S, Essén A, Lindgren P, et al. Managerial strategies to make incentives meaningful and motivating. J Health Organ Manag 2017;31:126-41. 